\title{
José Saramago “escrepintor”
}

\section{José Saramago "escrepintor"}

\author{
Denise Noronha Lima \\ Universidade Estadual do Ceará (UECE), Limoeiro do Norte, Ceará / Brasil \\ denise.noronha@uece.br
}

Resumo: Manual de pintura e caligrafia, de 1977, é o segundo romance publicado por José Saramago, três décadas após sua estreia na literatura. Considerando o valor transicional e formativo dessa obra, visto que ela antecede imediatamente a fase madura do autor, iniciada com Levantado do Chão, de 1980, este estudo busca examinar a forma como aquele movimento de transição se transfigura na narrativa, pela relação entre a pintura e escrita autobiográfica do protagonista. Procede-se à análise de diversos aspectos do diálogo entre literatura e pintura estabelecido no romance a partir da palavra "escrepintor", com a qual o narrador-personagem se define. Decorre da discussão desses aspectos a conclusão de que o Manual de pintura e caligrafia simboliza o nascimento de uma nova forma de narrativa de Saramago, cuja consolidação se efetivará na fase seguinte do escritor.

Palavras-chave: Saramago; pintura; romance.

Abstract: Manual of painting and calligraphy, 1977, is the second novel published by José Saramago, three decades after his debut in the literature. Considering the transitional and formative value of this work, since it immediately precedes the author's mature phase, which began with Raised from the ground, in 1980, this study aims to examine how that transitional movement is transformed in the narrative by the relationship between painting and autobiographical writing of the protagonist. It proceeds to the analysis of various aspects of the dialogue between literature and painting established in the novel from the word "escrepintor", with which the character storyteller defines himself. From the discussion of these aspects the conclusion is that the Manual of painting and calligraphy symbolizes the birth of a new form of Saramago's narrative, whose consolidation will take place in the next phase of the writer.

Keywords: Saramago; painting; novel. 
Recebido em: 29 de setembro de 2019.

Aprovado em: 11 de dezembro de 2019.

\section{Introdução}

Em 1977, José Saramago fez vir a público, após um intervalo de trinta anos, a sua segunda tentativa no romance: ${ }^{1}$ Manual de pintura e caligrafia. O enredo é construído a partir de múltiplas crises, das quais se destacam a crise existencial e artística do narrador-personagem, e a crise política da sociedade portuguesa às vésperas da Revolução de 25 de Abril, que poria fim ao longo período de ditadura salazarista. Paralelas durante a primeira parte do romance, essas crises confluirão em um segundo momento, decisivo para que se consolide o processo de formação artística e política do protagonista.

A relação entre literatura e pintura manifesta-se em Manual de pintura e caligrafia a partir do título. Antecede, porém, essa evidência o estranhamento causado pelo uso do vocábulo manual. Remetendo a uma noção prescritiva, por constituir geralmente um conjunto de regras de uma área do conhecimento ou instruções de uso de determinado objeto, a palavra manual pode, de fato, confundir o leitor por sua ambiguidade. Se a leitura desfaz a primeira impressão, por um lado, em relação ao conteúdo do livro, por outro mantém a sua essência, pois o romance será, com efeito, uma obra de aprendizagem.

\section{0 pintor aprendiz}

Insatisfeito com a pintura de retratos sob encomenda, o narradorpersonagem lamenta o que considera ser sua falta de talento para a grande Arte, como a italiana, que descreverá em seus exercícios de escrita. Homem de quase cinquenta anos, $\mathrm{H}$. estabelece uma correspondência entre a nulidade de sua arte e a de sua própria vida: sem família, com poucos amigos e, principalmente, sem um projeto que lhe dê perspectivas para o futuro, o protagonista entra num processo de autoanálise e

${ }^{1}$ Claraboia (2011), embora escrito na década de 1950, é uma publicação póstuma. 
autoconhecimento. H. busca conhecer (e revelar pela pintura) aquilo que a aparência esconde:

Toda a obra de arte, mesmo tão pouco merecedora como esta minha, deve ser uma verificação. Se quisermos procurar uma coisa, teremos de levantar as tampas (ou pedras, ou nuvens, mas vá por hipótese que são tampas) que a escondem. Ora, eu creio que não valeremos muito como artistas (e, obviamente, como homem, como gente, como pessoa) se, encontrada por sorte ou trabalho a coisa procurada, não continuarmos a levantar o resto das tampas, a arredar as pedras, a afastar as nuvens, todas, até ao fim (SARAMAGO, 1992, p. 276).

O problema, para esse aprendiz de artista, é não conseguir colocar em prática o que intui sobre a "verificação" que, segundo ele, a arte deve ser. Ao mesmo tempo que tem consciência em relação ao pouco valor da sua obra, deseja superar tal limitação. Para ele, o começo de um novo quadro é, por isso, sempre o desafio de quem está "por nascer". Encontramo-lo, no início do romance, diante deste impasse:

Molho o pincel e aproximo-o da tela, dividido entre a segurança das regras aprendidas no manual e a hesitação do que irei escolher para ser. Depois, decerto confundido, firmemente preso à condição de ser quem sou (não sendo) desde há tantos anos, faço correr a primeira pincelada e no mesmo instante estou denunciado aos meus próprios olhos. Como naquele desenho célebre de Bruegel (Pieter), aparece por trás de mim um perfil talhado a enxó, e ouço a voz dizer-me, uma vez mais, que não nasci ainda (SARAMAGO, 1992, p.6).

O desenho a que H. se refere é $O$ Pintor e o Comprador (1565), de Bruegel, o Velho (c.1526-1569). Nele, um pintor (que seria a representação do próprio Bruegel), tem por trás de si o comprador do quadro, estando ambos diante dessa obra, que não aparece, mas é sugerida. A postura do mercador é francamente interesseira, mais do que interessada, própria de quem calcula o lucro que obterá com a nova aquisição, opondo-se ao constrangimento do pintor, que desejaria talvez passar sua obra para as mãos de quem a reconhecesse como arte, e não mercadoria.

Esse incômodo de ser vigiado enquanto pinta é o elemento do desenho que Saramago transpôs para a sua personagem. A ideia de um olhar crítico, e não comercial, é coerente com o fato de que, em Portugal, 
essa obra de Bruegel recebeu o título de $O$ Pintor e o Crítico. Como crítico de si próprio, H. não se perdoa pela mediocridade de seus quadros. A tela vazia sempre lhe dá uma nova esperança, como no caso da encomenda de S., mas logo se anuncia o fracasso, que ele não evita: "E, contudo, não emendei nem voltei atrás, aceitei que as biqueiras apontassem o norte quando eu me deixava arrastar para o sul, para o mar dos sargaços, para a perdição dos navios, para o encontro com o holandês voador" (SARAMAGO, 1992, p. 10). Esta é a complexidade de sua situação: o norte da bússola, ao invés de indicar o rumo seguro, apenas o conduz ao resultado recorrente, que costuma agradar ao modelo, nunca ao pintor. Quanto às metáforas marítimas - o mar dos sargaços, por vezes chamado "cemitério de navios" (região cercada de correntes oceânicas, no meio do Atlântico Norte, com pouca vida marinha e abundância de algas que dificultam muito o curso das embarcações) e a lenda do holandês voador (navio fantasma condenado a nunca aportar, navegando contra o vento até o final dos tempos, e símbolo de má sorte) - são, por um lado, a representação da desorientação do pintor, e por outro, o desejo de mudança, talvez pelo desvio do caminho reto.

Apesar de H. manter-se obediente ao manual do bom retratista, desta vez, diante de S., algo diferente acontece: "bastou o primeiro olhar, e eu disse: 'Quem é este homem?' Esta é precisamente a pergunta que nenhum pintor deve fazer a si mesmo, e eu fi-la" (SARAMAGO, 1992, p. 14). A partir daí, começa o seu processo de "busca da verdade", como ele designará o conjunto de ações que vão desde a pintura de um retrato paralelo de S. até a escrita autobiográfica, além das reflexões sobre os acontecimentos que desencadeiam essa trajetória.

O primeiro indício de mudança que a pergunta "Quem é este homem?" provoca no íntimo do protagonista é a inclusão, no quadro solene, de "uma prega irônica que não tracei em nenhum lugar do rosto, que talvez não esteja sequer no rosto de S., mas que dá à tela uma deformação" (SARAMAGO, 1992, p. 14). A postura autoritária e insolente do modelo teria sido o principal fator desse incômodo profundo que mudará a sua vida.

Para resguardar-se de cometer uma deformação visível do retratado, que acarretaria naturalmente a perda do cliente, sem deixar de perscrutar a "verdade" de S., H. começa clandestinamente a pintura de um outro retrato desse modelo, mantido longe da vista dos frequentadores de seu ateliê. Será a sua segunda tentativa de compreensão: "Assim foi: 
falhei o primeiro retrato e não me resignei. Se S. me fugia, ou eu não o alcançava e ele sabia, a solução estaria no segundo retrato, pintado na ausência dele. Foi o que tentei. O modelo passou a ser o primeiro retrato e o invisível que eu perseguia" (SARAMAGO, 1992, p. 14). O resultado que ele busca terá como ponto de partida a "prega irônica" apenas insinuada, mas irreversível.

O projeto do pintor é ambicioso demais para um aprendiz: "tinha de aprender tudo se queria dividir nas suas minúsculas peças aquela segurança, aquele sangue-frio, aquela insolência todos os dias estudada para ferir onde mais doesse" (SARAMAGO, 1992, p. 14). Por isso, e acrescentando-se o fato de que ficava escondido, o segundo retrato de S. lembra o de Dorian Gray, que revelava a alma decrépita do jovem cuja aparência representava o ideal de beleza. Mesmo considerando a diferença em relação ao elemento fantástico que Oscar Wilde inclui em seu romance, fazendo com que "hora após hora, de semana a semana, a efígie na tela iria envelhecendo" (WILDE, 1998, p. 128), além de manifestar a vileza da personalidade do modelo, ambos os retratos se aproximam no ponto em que revelam a disparidade entre a aparência e a essência.

A busca do pintor, no entanto, não se resume a uma investigação filosófica - o que não seria pouco - sobre a dualidade acima descrita. A principal razão da insatisfação de $\mathrm{H}$. com sua pintura tem a ver com o fato de que, para ele, a verdadeira obra de arte revela a imagem do seu próprio autor. Como os retratos que pinta não são iguais ao que ele é, mas àquilo que fazem pensar dele, o resultado é sempre falso, embora academicamente bem realizado. Por outro lado, o pintor não está convicto de quem seja: "se não é antes verdade ser eu precisamente e apenas o que de mim querem" (SARAMAGO, 1992, p. 60). Daí o seu desalento inicial:

Quem retrata, a si mesmo retrata. Por isso, o importante não é o modelo mas o pintor, e o retrato só vale o que o pintor valer, nem um átomo a mais. O Dr. Gachet que Van Gogh pintou, é Van Gogh, não é Gachet, e os mil trajos (veludos, plumas colares de ouro) com que Rembrandt se retratou, são meros expedientes para parecer que pintava outra gente ao pintar uma diferente aparência. Disse que não gosto de minha pintura: porque não gosto de mim e sou obrigado a ver-me em cada retrato que pinto, inútil, cansado, desistente, perdido, porque não sou Rembrandt nem Van Gogh. Obviamente (SARAMAGO, 1992, p.79). 
Louis Lavelle (2012) faz uma análise filosófica que parece desenvolver, pela referência à pintura, essa constatação do protagonista, examinando a fundo a relação de identidade entre o eu e o outro a partir do mito de Narciso:

É o que se percebe bem no exemplo do pintor que, ao fazer seu próprio retrato, faz o retrato de um outro, e, quando faz o retrato de um outro, faz também o retrato de si mesmo. Pois ele só pode pintar o que ele não é, o que se distingue dele e o que se opõe a ele. Assim ele se obriga, quando pinta, a descobrir o rosto mesmo que os outros veem dele. Mas o retrato que ele faz de um outro é uma obra que vem dele e que mostra a todos os olhares o que ninguém veria de outro modo, e que é sua própria visão invisível do mundo (LAVELLE, 2012, p. 60).

Assim, o eu não apenas revela o outro, mas é revelado por ele. Utilizando a afirmação de Platão, segundo a qual nosso olho se percebe na pupila de outro olho, o filósofo estabelece uma relação especular e recíproca, análoga à do pintor que retrata a si mesmo ou ao outro. Em qualquer dessas situações, o resultado será sempre uma visão pessoal, influenciada, no entanto, pelo olhar do outro. A imagem que alguém tem de si incorpora o olhar do outro em sua formação; a imagem que faz do outro revela traços de sua própria identidade. Por isso, para H., seus quadros têm tão pouco valor quanto a imagem que tem de si próprio.

\section{O "escrepintor"}

Insatisfeito com essa imagem, mas ao mesmo tempo sem querer desistir de si, o narrador buscará outra forma de expressão e conhecimento. Para sair do impasse, $H$. inicia sua experiência com a escrita, ou caligrafia, como prefere chamar, considerando o seu caráter de aprendiz. Não se trata, no entanto, de uma substituição, pois a personagem transitará entre a escrita e a pintura, e, no âmbito desta, entre a arte convencional e a nova arte:

Tenho dois retratos em dois cavaletes diferentes, cada um em sua sala, aberto o primeiro à naturalidade de quem entra, fechado o segundo no segredo da minha tentativa também frustrada, e estas folhas de papel que são outra tentativa, para que vou de mãos nuas, sem tintas nem pincéis, apenas com esta caligrafia, este 
fio negro que se enrola e desenrola, que se detém em pontos, em vírgulas, que respira dentro de pequenas clareiras brancas e logo avança sinuosa, como se percorresse o labirinto de Creta ou os intestinos de S. (Interessante: esta última comparação veio sem que eu a esperasse ou provocasse. Enquanto a primeira não passou de uma banal reminiscência clássica, a segunda, pelo insólito, dá-me algumas esperanças: na verdade, pouco significaria se eu dissesse que tento devassar o espírito, a alma, o coração, o cérebro de S.: as tripas são outra espécie de segredo.) E tal como já disse logo na primeira página, andarei de sala em sala, de cavalete em cavalete, mas sempre virei dar a esta pequena mesa, a esta luz, a esta caligrafia, a este fio que constantemente se parte e ato debaixo da caneta e que, não obstante, é a minha única possibilidade de salvação e de conhecimento (SARAMAGO, 1992, p. 11).

O objetivo do pintor desdobra-se: deseja a salvação, que, no seu caso, significa tornar-se um verdadeiro artista; e almeja também o conhecimento, que, por enquanto, tem "a verdade de S." como alvo. H. parece intuir que a escrita lhe possibilitará desvendar aquilo que se esconde sob a superfície do modelo e do que ele representa.

Com o exercício da escrita, o pintor caminha, gradativamente, em direção a um outro ponto, desviando-se do que inicialmente havia planejado. Nas duas tentativas pictóricas, o retrato "oficial" de S. e, depois, o da sua "verdade", não atingiu seu intento. Múltipla, a verdade fugia-lhe:

Ora, que sei eu disso, da chamada verdade de S.? Quem é S. (esse)? Que é a verdade? perguntou Pilatos. Que é, repito, a verdade de S.? E que verdade, ou que coisa assim dizível, ou designável, ou classificável? A verdade biológica? a mental? a afectiva? a econômica? a cultural? a social? a administrativa? a de amante temporário e protector da menina Olga, sua quinta secretária? ou a verdade conjugal? a de marido que trai? a de marido por sua vez atraiçoado? a de jogador de bridge e de golfe? a de eleitor de governos fascistas? a da água-de-colónia que usa? a da marca dos seus três automóveis? a da água da piscina? a das suas obsessões sexuais? a das suas rugas verticais entre as sobrancelhas? a verdade da sombra que faz? da urina que verte? da voz que despediu há tempos trinta e quatro operários da primeira fábrica por causa da construção da segunda? a verdade das novas máquinas que dispensam desde já trinta e quatro operários e 
amanhã mais trinta e quatro? Que verdade, secretária Olga? (SARAMAGO, 1992, p. 62).

Essas várias "verdades", e outras mais que o narrador poderia enumerar, impelem-no ao aprofundamento daquela constatação inicial: "Quem retrata, a si mesmo retrata" (SARAMAGO, 1992, p. 79). Não tendo ainda consciência da dimensão dessa frase, H. antecipava, sem o saber, o resultado de sua busca: o pintor retrata o objeto não como este é, mas como ele o vê; por isso, o artista estará sempre presente em sua obra, tanto quanto aquilo que foi representado, pois tudo aparecerá segundo a subjetividade do autor.

Não é outra a opinião de Tzvetan Todorov (2014), ao analisar a pintura de Francisco de Goya. Procurando demonstrar que o pintor espanhol não foi apenas um dos principais artistas, mas também um dos pensadores mais profundos da sua época, Todorov parte da premissa de que, para Goya, "a descoberta da verdade à qual o pintor aspira, passa pela adequação entre a interioridade do indivíduo e os meios acionados, e não pela submissão às tradições comuns e às regras ensinadas nas academias" (TODOROV, 2014, p. 32). Ou, em outras palavras, "o pintor não deve mostrar o mundo tal como é, mas sua visão pessoal desse mundo" (TODOROV, 2014, p. 35). Descobrimos, assim, que o nosso pintor de retratos tem um antecedente ilustre nessa busca de uma verdade artística que, para ser encontrada, deve superar os manuais de pintura. Mas não de caligrafia, diria $\mathrm{H}$.

Escrevendo como quem quer "reconstruir tudo pelo lado de dentro" (SARAMAGO, 1992, p. 19), o narrador começa por si próprio a aprendizagem em relação a uma nova forma artística. Não para substituir a primeira, mas para ajudá-lo a atingir o grau de verdade que ambas podem revelar. Situação semelhante, guardadas as proporções de talento, à de Leonardo da Vinci, como relata Italo Calvino em sua conferência sobre a "Exatidão", uma das suas propostas para este milênio:

Leonardo - "omo sanza lettere" [homem sem letras], como se definia - tinha um relacionamento difícil com a palavra escrita. Ninguém possuía sabedoria igual no mundo em que viveu, mas a ignorância do latim e da gramática o impedia de se comunicar por escrito com os doutos do seu tempo. Sentia-se sem dúvida capaz de expressar pelo desenho, melhor do que pela palavra, uma larga parte de seu conhecimento. [...] Mas havia nele também uma necessidade imperiosa de escrever, de usar a escrita para 
explorar o mundo em suas manifestações multiformes, em seus segredos e ainda para dar forma às suas fantasias, às suas emoções, aos seus rancores. [...] Por isso escrevia cada vez mais: com o passar dos anos tinha parado de pintar, mas pensava escrevendo e desenhando, e, como que perseguindo um único discurso com desenhos e palavras, enchia seus cadernos com sua escrita canhota e especular (CALVINO, 1990, p. 92).

A escrita encerraria a busca de uma expressão mais fiel ao pensamento, que a pintura, por motivos diferentes em H. e em Da Vinci, não conseguia atingir. A julgar pela opinião de Calvino, não foi suficiente Da Vinci afirmar que "a diversidade em que se estende a pintura é incomparavelmente maior que a que encerra as palavras, pois o pintor fará uma infinidade de coisas que as palavras não poderão designar, por falta de vocábulos apropriados" (DA VINCI, 2008, p. 18-21). Se, ao contrário desse elogio da pintura, para o artista italiano a escrita seria, no dizer de Calvino, o meio de "explorar o mundo em suas manifestações multiformes", e também "dar forma às suas fantasias, às suas emoções, aos seus rancores", para H. ela é, como vimos, a única possibilidade de salvação e de conhecimento.

As relações de H. e Da Vinci com a pintura e a escrita são desdobramentos de uma doutrina que tem produzido diversas análises desde o Renascimento, a do "Ut pictura poesis" ("Poesia é como pintura"). Como é sabido, essa frase, que nomeia a mais alimentada discussão sobre o paralelo das artes, foi retirada da Epístola aos Pisões, de Horácio (65-8 A.C.), conhecida também como Arte poética (1997). Nela, o poeta romano baseia-se em leis poéticas indispensáveis para a composição da obra de arte, para aconselhar os Pisões, pai e filhos, na criação e no julgamento artístico. O fundamental, para Horácio, está na ordem dos elementos segundo uma lógica interna da obra, que só assim adquire unidade, característica vital para a arte. $\mathrm{O}$ trecho que deu origem ao tema clássico do "Ut pictura poesis" é o seguinte:

Poesia é como pintura; uma te cativa mais, se te deténs mais perto; outra, se te pões mais longe; esta prefere a penumbra; aquela quererá ser contemplada em plena luz, porque não teme o olhar penetrante do crítico; essa agradou uma vez; essa outra, dez vezes repetida, agradará sempre (HORÁCIO, 1997, p. 65). 
Pode-se inferir desse trecho que a lição de Horácio identifica semelhanças entre a pintura e a poesia, numa comparação que não estimula a competição entre as artes, como ocorrerá ao ser retomada séculos mais tarde. No entanto, a simples comparação carrega em si um aspecto hierárquico, pois Horácio toma a pintura como referência, elevando-a em relação à poesia. Ocorre que a doutrina renascentista do "Ut pictura poesis" teria se baseado numa distorção interpretativa dessa comparação:

Ao retomarem a frase de Horácio, os teóricos do Renascimento inverteram o sentido da comparação: a poesia tornou-se o termo comparativo e a pintura o termo comparado. Ut pictura poesis erit tornou-se, para eles, Ut poesis pictura, a pintura é como a poesia, o quadro é como o poema. E foi esse sentido, ou melhor, essa inversão de sentido, que a tradição conservou (LICHTENSTEIN, 2008, p. 10).

A autora acrescenta que essa inversão de sentido não resulta de um simples erro de tradução, mas de uma estratégia a favor da pintura, mesmo esta não sendo mais o termo referente. Para os renascentistas, importava demonstrar, por um lado, que a pintura merecia o reconhecimento como uma atividade liberal, ou seja, digna de um homem livre, e, por outro, desfazer a suspeição platônica de arte ilusória que pesava sobre ela, mostrando que era também uma forma de saber.

A necessidade de legitimar a pintura, que teria motivado a inversão dos termos da comparação, parece sugerir que a "primogenitura" dessa arte não lhe garantiu a superioridade em relação à poesia, aspecto que Saramago abordará em História do cerco de Lisboa (1989). No primeiro capítulo, em diálogo com o historiador de quem está revisando o livro que tem o mesmo título do romance, Raimundo Silva alega a supremacia da literatura, numa visão generalizadora do problema:

[...] em minha discreta opinião, senhor doutor, tudo quanto não for vida, é literatura, A história também, A história sobretudo, sem querer ofender, E a pintura, e a música, A música anda a resistir desde que nasceu, ora vai, ora vem, quer livrar-se da palavra, suponho que por inveja, mas regressa sempre à obediência, $\mathrm{E}$ a pintura, Ora, a pintura não é mais do que literatura feita com pincéis, Espero que não esteja esquecendo de que a humanidade começou a pintar muito antes de saber escrever, Conhece o rifão, 
se não tens cão caça com o gato, por outras palavras, quem não pode escrever pinta, ou desenha, é o que fazem as crianças, O que você quer dizer, por outras palavras, é que a literatura já existia antes de ter nascido, Sim senhor, como o homem, por outras palavras, antes de o ser já o era (SARAMAGO, 1989, p. 15).

Aparentemente simplificadora, a opinião do revisor encerra um conceito amplo de ficcionalidade, segundo o qual "tudo quanto não for vida, é literatura". Em relação à História, tal concepção aproxima-se de teorias recentes nessa área, como aquelas que admitem a ficcionalização do discurso histórico. Desse ponto de vista, os acontecimentos do passado, ao sofrerem a intervenção da imaginação do historiador no preenchimento de lacunas deixadas por documentos escritos ou por memórias pessoais ou coletivas, por exemplo, recebem uma elaboração narrativa semelhante à que faz a literatura, e o fato histórico ganha a ambiguidade da ficção.

A ideia de "literatura feita com pincéis" estaria em germe no conceito, criado por H., de "escrepintar": "esse novo e universal esperanto que a todos nós transformaria em escrepintores, então talvez dignos práticos de bentas artemages" (SARAMAGO, 1992, p. 170). Situado entre a pintura e a escrita, $H$. é, na realidade, um duplo aprendiz: se as impossibilidades da pintura o levaram a escrever, "falta, para que fique definitivamente provada a justiça deste mundo, que as ambiguidades da escrita, e as suas por sua vez impossibilidades, me venham a fazer pintar. Ou alguma coisa intermédia" (SARAMAGO, 1992, p. 170). Essa atividade intermédia seria a "escrepintura", de que o Manual de pintura e caligrafia poderia ser considerado o primeiro fruto.

É possível identificar três estágios por que passa o protagonista durante o seu trânsito entre a pintura e a caligrafia. Inicialmente, sua reação diante da novidade que é, para si, o ato de escrever, é uma espécie de deslumbramento. Embora pense que "as diferenças não são muitas entre palavras que às vezes são tintas, e as tintas que não conseguem resistir ao desejo de quererem ser palavras" (SARAMAGO, 1992, p.97), reconhece na escrita uma vantagem sobre a pintura:

Observo-me a escrever como nunca me observei a pintar, e descubro o que há de fascinante neste acto: na pintura, vem sempre o momento em que o quadro não suporta nem mais uma pincelada (mau ou bom, ela irá torná-lo pior), ao passo que estas linhas podem prolongar-se infinitamente, alinhando parcelas de uma 
soma que nunca será começada, mas que é, nesse alinhamento, já trabalho perfeito, já obra definitiva porque conhecida. É sobretudo a ideia de prolongamento infinito que me fascina (SARAMAGO, 1992, p. 16).

A aventura da liberdade, que o pintor nunca conseguiu com sua obra, agora lhe abre inúmeras possibilidades. Essa descontração o levará naturalmente a um segundo estágio, que inclui o caráter lúdico da escrita e o encorajamento do pintor em "retratar", narrando, a sua realidade:

Brinco com as palavras como se usasse as cores e as misturasse ainda na paleta. Brinco com estas coisas acontecidas, ao procurar palavras que as relatem mesmo só aproximadamente. Mas em verdade direi que nenhum desenho ou pintura teria dito, por obras de minhas mãos, o que até este preciso instante fui capaz de escrever, e atrever (SARAMAGO, 1992, p. 54).

Para além da fascinação pela escrita, H. procura "distinguir entre o que é verdade de dentro e pele luzidia [...]. Separar, dividir, confrontar, compreender. Perceber. Exactamente o que não pude alcançar nunca enquanto pintei" (SARAMAGO, 1992, p. 21). Por isso mesmo, começou a escrever dois dias depois de pressentir e destino do segundo retrato, ou seja, quando percebeu que falharam as duas tentativas na pintura. Aos poucos, sua descontração diante da folha em branco substituirá o medo do fracasso, embora, na realidade, não tenha bem definido o objetivo de sua escrita: "Não sei que passos darei, não sei que espécie de verdade busco: apenas sei que se me tornou intolerável não saber" (SARAMAGO, 1992, p. 15). Aproxima-se agora do terceiro estágio de sua transição, que é a investigação não mais do outro, mas de si próprio por meio da escrita:

Visto a distância (vestir a distância), tenho os gestos de Rembrandt. Tal como ele, misturo as cores na paleta, tal como ele, alongo o braço firme que não hesita na pincelada. Mas a tinta não fica posta da mesma maneira, há uma torção a mais ou a menos do pulso, uma pressão maior ou menor dos pêlos de marta (não de Marta) do pincel: ou não usava Rembrandt pincéis de pêlo de marta, e toda a diferença está precisamente aí? Se mandasse fazer uma macrofotografia de pormenor de um quadro de Rembrandt, não veria confirmada essa diferença? E a diferença não será precisamente a que separa o génio (Rembrandt) da nulidade (eu) (Entre parêntesis: meti entre parêntesis Rembrandt e eu para que 
não ficasse escrito "o génio da nulidade", absurdo que nem mesmo um aprendiz de primeiras letras, qual sou, deixaria escapar.) Mas como os pintores meus contemporâneos usam todos pincéis iguais ou semelhantes a estes, outras diferenças há-de haver para que a crítica os louve a eles, e a mim não, para que eles, embora diferentes entre si, sejam todos melhores do que eu, e eu pior que todos eles. Questão de pulso? Questão de quê? (SARAMAGO, 1992, p. 70).

Questão de espírito, diria Charles Blanc. Em sua Gramática das artes do desenho, de 1867, o crítico de arte argumenta que a pincelada define o estilo do pintor, conferindo-lhe um caráter à sua obra: "A pincelada está para a pintura mais ou menos como a grafia está para a caligrafia. [...] é a caligrafia do pintor, é a marca de seu espírito. [...] a pincelada do pintor sempre será boa quando for natural, ou seja, quando vier do seu coração." (BLANC apud LICHTENSTEIN, 2014, p. 64).

O pensamento de Blanc não difere, em essência, daquele expresso por H. em seus escritos: "Quem retrata, a si mesmo retrata. Por isso, o importante não é o modelo mas o pintor, e o retrato só vale o que o pintor valer, nem um átomo a mais" (SARAMAGO, 1992, p. 79). O "si mesmo" a que $\mathrm{H}$. se refere corresponde ao caráter de que fala Blanc. Para este, o quadro será tanto melhor quanto mais natural, e será natural quando o artista transfigurar na obra o "seu coração". Ressalte-se que nem $H$. nem Charles Blanc referem-se à vida pessoal dos pintores, mas àquilo que define o seu "eu". A obra revela o próprio artista, na medida em que este deixa nela a marca de sua subjetividade.

$\mathrm{Se} \mathrm{H}$. admitia, desde o início de sua narrativa, a tese de que a obra revela a imagem do seu autor, martirizava-o, no entanto, o fato de não conseguir superar o estágio primário de sua pintura, representado pelo seu aprisionamento às regras básicas de um manual. Em outras palavras, afligia-o a sua falta de originalidade, que estaria relacionada à ausência de si mesmo na obra.

Um episódio inesperado, porém, mudará decisivamente o curso de sua vida. Em reunião de amigos para festejar a venda do quadro (o único retrato de $\mathrm{S}$. concluído), Antônio descobre o segundo retrato, ou o que dele restara: segura na frente de todos - "com um sorriso fixo, decidido, que poderia ser de maldade, mas no António não, calado António e secreto" (SARAMAGO, 1992, p. 85) - a tela clandestina, coberta com a tinta preta com que $\mathrm{H}$. sepultara a vergonha de mais um 
fracasso. O constrangimento, a raiva, a humilhação, todos os sentimentos que a exposição da tela provocara deram lugar, depois, à mais profunda reflexão do protagonista sobre a sua vida e a sua obra:

Pus-me então a estudar a minha vida, a vê-la devagar, a remexerlhe como quem levanta pedras à procura de diamantes, bichos-deconta ou grossas larvas, dessas brancas e gordas que nunca tinham visto o sol e de repente o sentem na pele macia, como um fantasma eu doutra maneira se não revelará (SARAMAGO, 1992, p. 90).

Denominamos "epifania" esse momento porque ele se insere entre os "últimos instantes de inconsciência" do narrador-personagem e a decisão que lhe segue: a de escrever, agora deliberadamente e não por digressões provocadas pela busca do outro, a sua própria vida, concedendo à memória o espaço que lhe cabe nessa transformação. É esse o terceiro estágio da transição de $\mathrm{H}$. entre a pintura e a caligrafia. Mas a sua convicção sobre o fato de que quem retrata, a si mesmo retrata, transforma-se em dúvida quando a indagação recai sobre a escrita:

Mas quem escreve? Também a si escreverá? Que é Tolstoi na Guerra e Paz? Que é Stendhal na Cartuxa? É a Guerra e Paz todo o Tolstoi? É a Cartuxa todo o Stendhal? Quando um e outro acabaram de escrever estes livros, encontraram-se neles? Ou acreditaram ter escrito rigorosamente e apenas obras de ficção? E como de ficção, se parte dos fios da trama são história? Que era Stendhal antes de escrever a Cartuxa? Que ficou sendo depois de a escrever? E por quanto tempo? Não passou mais de um mês desde o dia em que comecei este manuscrito, e não me parece que seja hoje quem era então. Por ter somado mais trinta dias ao meu tempo de vida? Não. Por ter escrito. (SARAMAGO, 1992, p. 79)

Para tantas perguntas, no entanto, não se deve deduzir que o pintor não tenha respostas, afinal já tem a sua própria experiência para tentar compreender a relação entre o escritor e sua obra. Assim, se quem retrata, a si mesmo retrata, é possível que um processo semelhante ocorra com quem escreve. Se o Dr. Gachet é o próprio Van Gogh, por que não seriam as personagens de Guerra e paz e A cartuxa de Parma um retrato de Tolstoi e Stendhal, respectivamente? H. declara ter-se modificado com a sua caligrafia. De fato, para ele a escrita será o meio de se descobrir, e só assim poder se revelar na sua pintura. 


\section{Considerações finais}

O percurso de José Saramago, na literatura, até a consolidação do seu estilo, ou seja, de uma marca própria que passou a ser reconhecida pelos leitores a cada novo livro, pode ser dividido em duas grandes fases (que, por sua vez, contêm pequenas divisões). A primeira, cujo início remonta a 1947, com Terra do pecado, para apenas continuar em 1966, compreende aquele romance e os livros de poesia, crônica e algum teatro, variedade que indica talvez a busca do escritor por um gênero em que realmente se sentisse à vontade para explorar toda uma potencialidade que germinava nesses primeiros escritos. Isso ocorreria na segunda fase, a partir de Levantado do chão, de 1980, e a consagração do autor com Memorial do convento, de 1982. Entre as duas fases encontra-se Manual de pintura e caligrafia, romance que revela a situação do escritor em formação, qual o protagonista pintor.

Obra de transição, portanto, o Manual tem importância não apenas pelo seu valor estético, mas por transfigurar com profundidade $o$ processo de aprendizagem do escritor, numa espécie de poética da criação literária, que a pintura ajudou a construir. Romance de formação dupla, a do protagonista e a de seu autor, essa obra se encerra anunciando o porvir de um novo homem e de sua voz.

\section{Referências}

BLANC, C. Gramática das artes do desenho. In: LICHTENSTEIN, J. (dir.). A pintura: textos essenciais. v. 13: O ateliê do pintor. Coordenação da tradução: Magnólia Costa. São Paulo: Ed. 34, 2014.

CALVINO, I. Seis propostas para o próximo milênio: lições americanas. 3. ed. Tradução de Ivo Barroso. São Paulo: Companhia das Letras, 1990. HORÁCIO. Arte poética. In: ARISTÓTELES. HORÁCIO. LONGINO. A poética clássica. Tradução de Jaime Bruna. 7. ed. São Paulo: Cultrix, 1997.

LAVELLE, L. O erro de Narciso. Tradução de Paulo Neves. São Paulo: É Realizações, 2012.

LICHTENSTEIN, J. (org.). A pintura: textos essenciais. Coordenação da tradução: Magnólia Costa. São Paulo: Ed. 34, 2008. 
SARAMAGO, J. Claraboia. São Paulo: Companhia das Letras, 2011. SARAMAGO, J. História do cerco de Lisboa. São Paulo: Companhia das Letras, 1989.

SARAMAGO, J. Levantado do chão. 9. ed. Rio de Janeiro: Bertrand Brasil, 2000.

SARAMAGO, J. Manual de pintura e caligrafia. São Paulo: Companhia das Letras, 1992.

SARAMAGO, J. Memorial do convento. Rio de Janeiro: Bertrand Brasil, 2001.

SARAMAGO, J. Terra do pecado. 3. ed. Lisboa: Caminho, 1998.

TODOROV, T. Goya à sombra das luzes. Tradução de Joana Angélica d'Ávila Melo. São Paulo: Companhia das Letras, 2014.

WILDE, O. O retrato de Dorian Gray. Tradução de Marina Guaspari. Rio de Janeiro: Ediouro; São Paulo: Publifolha, 1998. 